\title{
FURTHER SELECTION EXPERIMENTS ON INDUSTRIAL MELANISM IN THE LEPIDOPTERA
}

\author{
Dr H. B. D. KETTLEWELL \\ Genetic Laboratories, Department of Zoology, University of Oxford
}

Received 22.iii.56.

\section{PREVIOUS EXPERIMENTS}

IN a previous paper (Kettlewell, I955), I recorded the results of extensive mark-release-recapture experiments undertaken in 1953 on the Peppered Moth, Biston betularia Linn. and its two melanic forms, carbonaria Jordan and insularia Th-Mieg (plate II, fig. 6). These experiments were carried out in a circumscribed area of woodland, the Christopher Cadbury Bird Reserve, situated about six miles from the industrial and heavily polluted area of Birmingham. The results then obtained may be summarised as follows :

(a) When released on to available trunks and boughs, their normal resting places, over 97 per cent. of carbonaria (the black form) appeared to the human eye to be inconspicuous. Conversely, nearly 89 per cent. of the light form of the Peppered Moth were adjudged conspicuous (plate I, fig. 2).

(b) Direct observation on the released insects showed that by late afternoon 54 per cent. of the light form had disappeared but only 37 per cent. of the carbonaria. Furthermore, we witnessed both Robins (Erithacus rubecula L.) and Hedge Sparrows (Prunella modularis L.) take the moths from off the trees, and they did this selectively and, on the majority of occasions, in an order of conspicuousness as previously scored by us.

(c) Recapture figures, reflecting a differential mortality rate, showed that more than twice as many carbonaria survived as typical ( 27.5 to 13 per cent.) (fig. I $a$ ).

These experiments showed that birds act as selective agents and that the melanic forms of betularia are at a cryptic advantage in an industrial area such as Birmingham. It was essential to repeat these observations during a subsequent season and to extend them by carrying out comparable mark-release-recapture experiments in unpolluted countryside. This paper provides details of such work, which was undertaken in 1955 .

\section{A REPEAT OF THE SELECTION EXPERIMENTS IN THE BIRMINGHAM DISTRICT}

Immediately following successful mark-release-recapture experiments in the summer of 1955 in an unpolluted wood in Dorset (recorded later in this paper) we moved camp to the Christopher Cadbury Bird 
TABLE I

Release experiments for $\mathrm{B}$. betularia (males only)

Rubery, near Birmingham, 1955

\begin{tabular}{|c|c|c|c|c|c|c|c|c|c|c|c|}
\hline \multirow{2}{*}{ Date } & \multicolumn{3}{|c|}{ Releases } & \multirow{2}{*}{ Total } & \multicolumn{3}{|c|}{ Catches } & \multirow{2}{*}{ Total } & \multicolumn{2}{|c|}{ Recaptures } & \multirow{2}{*}{ Total } \\
\hline & C & $\mathrm{T}$ & I & & C & $\mathrm{T}$ & I & & $\mathrm{T}$ & I & \\
\hline 8.7 & 54 & 23 & (5) & 82 & 62 & 7 & 5 & 74 & $\ldots$ & $\ldots$ & $\ldots$ \\
\hline 9.7 & $\ldots$ & $\ldots$ & IJ & $\ldots$ & 73 & I I & I & 85 & II & $\dddot{0}$ & $\dddot{44}$ \\
\hline 10.7 & 100 & 41 & (4) & 145 & $5^{1}$ & 5 & 2 & $5^{8}$ & 2 & 0 & 5 \\
\hline 11.7 & $\cdots$ & $\cdots$ & $\cdots$ & $\cdots$ & 50 & 7 & 2 & 59 & 2 & (2) & 50 \\
\hline 12.7 & $\ldots$ & $\ldots$ & $\ldots$ & $\ldots$ & 89 & 7 & 5 & 101 & I & 0 & 1 \\
\hline 13.7 & $\ldots$ & $\cdots$ & $\ldots$ & $\cdots$ & 25 & 4 & 0 & 29 & $\ldots$ & $\ldots$ & $\ldots$ \\
\hline 14.7 & $\cdots$ & $\ldots$ & $\ldots$ & $\cdots$ & 53 & 2 & 1 & $5^{6}$ & $\cdots$ & $\cdots$ & $\ldots$ \\
\hline 15.7 & $\cdots$ & $\cdots$ & $\cdots$ & $\cdots$ & 20 & 2 & 2 & 24 & $\cdots$ & $\cdots$ & $\ldots$ \\
\hline 16.7 & $\cdots$ & $\ldots$ & $\ldots$ & ... & 13 & 2 & 0 & 15 & $\ldots$ & $\ldots$ & $\ldots$ \\
\hline 17.7 & $\cdots$ & $\cdots$ & $\ldots$ & $\ldots$ & 20 & 2 & 0 & 22 & $\ldots$ & $\ldots$ & $\ldots$ \\
\hline 18.7 & $\cdots$ & $\cdots$ & $\cdots$ & $\cdots$ & 15 & 2 & 2 & 19 & $\cdots$ & $\cdots$ & $\cdots$ \\
\hline 19.7 & $\cdots$ & $\cdots$ & $\ldots$ & $\cdots$ & 5 & 1 & 0 & 6 & $\ldots$ & $\ldots$ & $\ldots$ \\
\hline 20.7 & $\cdots$ & $\ldots$ & ... & $\cdots$ & 10 & 1 & 0 & II & $\ldots$ & $\ldots$ & $\ldots$ \\
\hline \multirow[t]{3}{*}{ Totals } & $x_{54}$ & 64 & (9) & 227 & 486 & 53 & 20 & 559 & $x 6$ & 2 & 100 \\
\hline & & & & \multicolumn{3}{|c|}{1955} & \multirow{2}{*}{ Total } & \multicolumn{3}{|c|}{ 1953 } & \multirow{2}{*}{ Total } \\
\hline & & & & C & $\mathrm{T}$ & I & & C & $T$ & I & \\
\hline \multicolumn{4}{|c|}{$\begin{array}{l}\text { Wild Birmingham population } \\
\text { per cent. phenotype (fig. II) }\end{array}$} & 86.94 & $9 \cdot 48$ & 3.58 & 559 & 85.03 & $I O \cdot I_{4}$ & $4 \cdot 83$ & 621 \\
\hline \multicolumn{4}{|c|}{$\begin{array}{l}\text { Per cent. return of releases }= \\
\text { recaptures }\end{array}$} & $53 \cdot 25$ & 25 & $(22 \cdot 2)$ & 100 & 27.5 & $13^{\circ} \mathrm{O}$ & $17 \cdot 4$ & 149 \\
\hline
\end{tabular}

The letters C, T, and I stand for carbonaria, typical and insularia respectively throughout this paper

TABLE IA

Birmingham recaptures, 1953 (See Appendix)

\begin{tabular}{|c|c|c|c|c|c|c|c|}
\hline \multirow{2}{*}{ Date } & \multicolumn{3}{|c|}{ Observed } & \multirow{2}{*}{ Total } & \multicolumn{3}{|c|}{ Expected } \\
\hline & $\mathrm{C}$ & $\mathrm{T}$ & I & & $\mathrm{C}$ & $\mathrm{T}$ & I \\
\hline 25.6 & 5 & 1 & 2 & 8 & $2 \cdot 50$ & 3.00 & 2.50 \\
\hline 26.6 & o & 0 & 0 & 0 & 0 & o & 0 \\
\hline 27.6 & 0 & I & 2 & 3 & 1 68 & 0.56 & 0.76 \\
\hline $28 \cdot 6$ & 9 & 4 & 2 & 15 & $8 \cdot 8 \mathrm{I}$ & 5.00 & $1 \cdot 19$ \\
\hline $29 \cdot 6$ & o & o & 0 & 0 & 0 & 0 & 0 \\
\hline 30.6 & 17 & 2 & I & 20 & 13.89 & $5 \cdot 10$ & $1 \cdot 57$ \\
\hline 1.7 & $4^{1}$ & 6 & 0 & 47 & 37.11 & 8.66 & $\mathrm{I} \cdot 24$ \\
\hline 2.7 & 30 & 2 & I & 33 & $24 \cdot 92$ & $7 \cdot 07$ & $1 \cdot 01$ \\
\hline 3.7 & 26 & 2 & 0 & 28 & $22 \cdot 94$ & 5.06 & \\
\hline $4 \cdot 7$ & 12 & 0 & 0 & 12 & 10.18 & $1 \cdot 5^{2}$ & 0.30 \\
\hline Totals & 140 & 18 & 8 & 166 & $121 \cdot 46$ & $35 \cdot 97$ & $8 \cdot 57$ \\
\hline
\end{tabular}


Reserve near Birmingham, which I had chosen in I953 as being likely to offer the optimum conditions for my requirements. I had three objects in view in this undertaking. Firstly to repeat a small markrelease experiment similar to that of 1953. Secondly, to give $\mathrm{Dr}$ Tinbergen an opportunity of filming the experiments so as to make
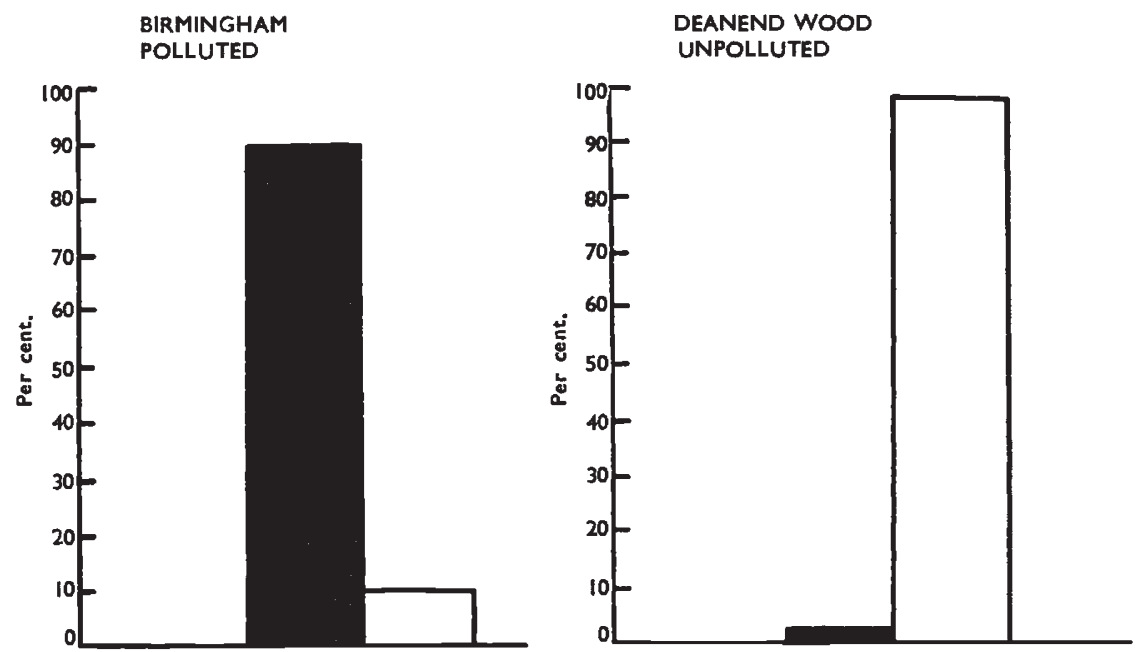

FIG. I.-Local Population Frequencies.

POLLUTED

UNPOLLUTED
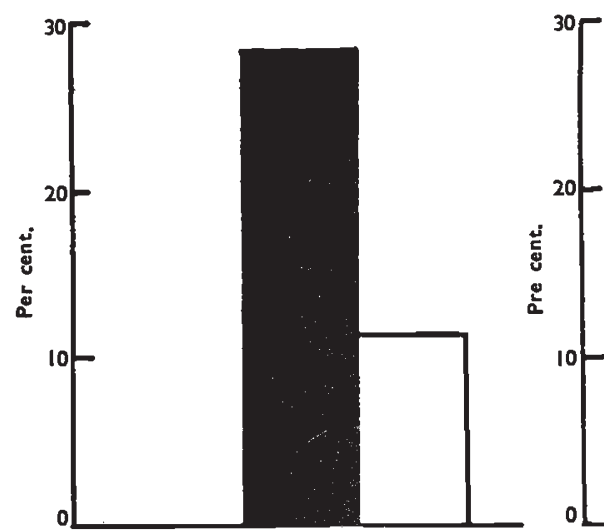

Fig. Ia.-Recapture Frequencies.

a visual record of them in the same way that he had done previously in Dorset, and thirdly to check the local phenotype frequencies, after having released 137 male and 34 female typical betularia in 1953 .

(a) Mark-release-recapture results. Altogether a total of 227 betulnria were released over two periods, 154 carbonaria, 64 typical (and 9 insularia), see table I. Of these, I recaptured a total of Ioo, 82 being carbonaria, I6 typical (and 2 insularia), see tables I and IA. This represents a 
return of 52.25 per cent. of the carbonaria release and 25 per cent. of the typical (insularia 22.2). Once again we recaptured twice as many of the black form as of the light, but this differed from the 1953 releases which were spread over II days, when we recaught 27.5 per cent. of carbonaria and 13 per cent. of typical. Whether the present increased return rate was due to the greater efficiency of our recapture

TABLE 2

Observation on predation of B. betularia, by Redstarts for 2 days only (by $\operatorname{Dr} \mathcal{N}$. Tinbergen from his hide), Birmingham, 1955

\begin{tabular}{|c|c|c|c|}
\hline & Typical & Carbonaria & Total \\
\hline 19.7 a.m. & 12 & 3 & 15 \\
20.7 a.m. & 14 & 3 & 17 \\
p.m. & 17 & 9 & 26 \\
\hline Total . & 43 & 15 & $5^{8}$ \\
\hline
\end{tabular}
taken.

$\mathcal{N} . B$.- Replenished to equality as soon as all three of either phenotype had been

methods, or to decreased predation, diminished migration or a small natural population, I am unable to say. But it is important to note that the relative return figures were of the same order as in my previous series of experiments.

(b) Dr Tinbergen succeeded in filming Redstarts (Phonicurus phanicurus L.) taking and eating our releases (plate II, fig. 5), and I am able to give in table 2 his records of the predation which took

TABLE 3

Comparative methods of collecting at M.V. light and assembling traps for 6 nights only. Birmingham, 1955

\begin{tabular}{|c|c|c|c|c|c|c|c|c|c|c|c|c|c|c|c|c|c|c|c|c|c|}
\hline \multirow[b]{2}{*}{ Phenotypes } & \multicolumn{3}{|c|}{ 8th July } & \multicolumn{3}{|c|}{$9^{\text {th }}$ July } & \multicolumn{3}{|c|}{ I oth July } & \multicolumn{3}{|c|}{ I I th July } & \multicolumn{3}{|c|}{ I 2th July } & \multicolumn{3}{|c|}{ I $3^{\text {th }}$ July } & \multicolumn{3}{|c|}{ Totals } \\
\hline & C & $\mathrm{T}$ & I & C & $\mathbf{T}$ & I & C & $\mathbf{T}$ & I & C & $\mathbf{T}$ & I & C & $\mathbf{T}$ & I & C & $\mathrm{T}$ & I & C & $\mathbf{T}$ & I \\
\hline M.V. light traps & 32 & 6 & 2 & 9 & 5 & o & 23 & 4 & 2 & 19 & I & 0 & 72 & 7 & 4 & 12 & 2 & o & $x 67$ & 25 & 8 \\
\hline Assembling traps & 30 & I & 3 & 97 & 17 & I & $3^{\mathrm{I}}$ & 3 & o & 77 & 8 & 4 & 17 & I & I & 3 & 0 & 2 & 255 & 30 & 10 \\
\hline
\end{tabular}

place on two days whilst he kept observation from a hide. In each case the two forms were released in equality and subsequently replenished at intervals after all of one form had been taken. In this way, he recorded that 43 of the pale typical form were eaten to 15 of the black form carbonaria and, on the majority of occasions, two or more typicals were eaten before a carbonaria was discovered. Once again 
we were able to show that the presence of a conspicuous light coloured typical immediately put the better hidden carbonaria at a disadvantage which they would not otherwise have incurred if they had been released on their own.

(c) A total of 559 wild betularia were caught over a period of I3 nights, carbonaria 486, typical 53 and insularia 20, giving the percentages respectively of $86.94,9.48$ and 3.58 (see table 1 ). This compares with 62 I betularia taken over I I nights in 1953 with carbonaria 85.03 per cent., typical ${ }_{10} \cdot 14$ per cent. and insularia 4.83 per cent. Furthermore, table 3 demonstrates that for the 6 nights on which light and assembling traps were both in operation the total catch (= wild population + releases) showed a similar proportion of each phenotype as coming to both methods of collecting. It again compares with the high degree of consistency with my 1953 figures, see table $3 \mathrm{~A}$.

TABLE 3A

Comparison of the proportion (per cent.) of phenotypes which came to $M . V$. light and to assembling

\begin{tabular}{|c|c|c|c|c|c|c|c|c|}
\hline Year & \multicolumn{4}{|c|}{$\begin{array}{c}\text { Birmingham } \\
\text { I } 953 \text { (for Io nights) }\end{array}$} & \multicolumn{4}{|c|}{$\begin{array}{c}\text { Birmingham } \\
\text { I } 955 \text { (for } 6 \text { nights) }\end{array}$} \\
\hline Phenotypes & C & $\mathrm{T}$ & I & Total & C & $\mathrm{T}$ & I & Total \\
\hline $\begin{array}{l}\text { M.V. light- } \\
\text { Totals } \\
\text { Percentage }\end{array}$ & $\begin{array}{c}263 \\
83 \cdot 60\end{array}$ & $\begin{array}{c}47 \\
10 \cdot 85\end{array}$ & $\begin{array}{c}24 \\
5 \cdot 55\end{array}$ & $\begin{array}{l}433 \\
100\end{array}$ & $\begin{array}{c}167 \\
86 \cdot 44\end{array}$ & $\begin{array}{c}25 \\
10 \cdot 17\end{array}$ & $\begin{array}{r}8 \\
3 \cdot 39\end{array}$ & $\begin{array}{l}200 \\
100\end{array}$ \\
\hline $\begin{array}{c}\text { Assembling- } \\
\text { Totals } \\
\text { Percentage }\end{array}$ & $\begin{array}{c}281 \\
85 \cdot 68\end{array}$ & $\begin{array}{c}34 \\
10 \cdot 36\end{array}$ & $\begin{array}{c}13 \\
3 \cdot 96\end{array}$ & $\begin{array}{l}328 \\
100\end{array}$ & $\begin{array}{r}255 \\
83.5\end{array}$ & $\begin{array}{r}30 \\
12 \cdot 5\end{array}$ & $\begin{array}{c}10 \\
4\end{array}$ & $\begin{array}{l}295 \\
100\end{array}$ \\
\hline
\end{tabular}

This small repeat experiment fully corroborated the findings of the previous one, namely that the pale typical form, as found in unpolluted countryside, is at a cryptic disadvantage in an industrial area. The fact that birds eliminate these selectively, thereby affecting the evolution of the Peppered Moth, was again recorded.

\section{SELECTION EXPERIMENTS IN UNPOLLUTED COUNTRYSIDE}

It can be presumed that melanic mutations take place at intervals throughout the range of Biston betularia. To test their selective advantages or disadvantages by mark-release-recapture experiments, it would be advantageous, therefore, to choose a location where the melanic carbonaria was only maintained by recurrent mutation. A wood having such specifications and, at the same time, suitable in other requirements such as offering isolation and free access by rides was not easy to find. Moreover, amenities for housing the very large 
number of pupæ necessary to ensure specimens for release had to be available on the site. A large number of woods in Devon and Cornwall, where only the typical light coloured form of Biston betularia occurs, were investigated, but were found to be unsuitable for one reason or another. Eventually a peninsula of extremely heavily lichened woodland was found in Deanend Wood, Dorset (fig. 2), and in I954 I was able to visit it for a single night with a view to collecting a random sample of betularia Twenty specimens were taken assembling to virgin females, of which 19 were typical and I insularia. There were

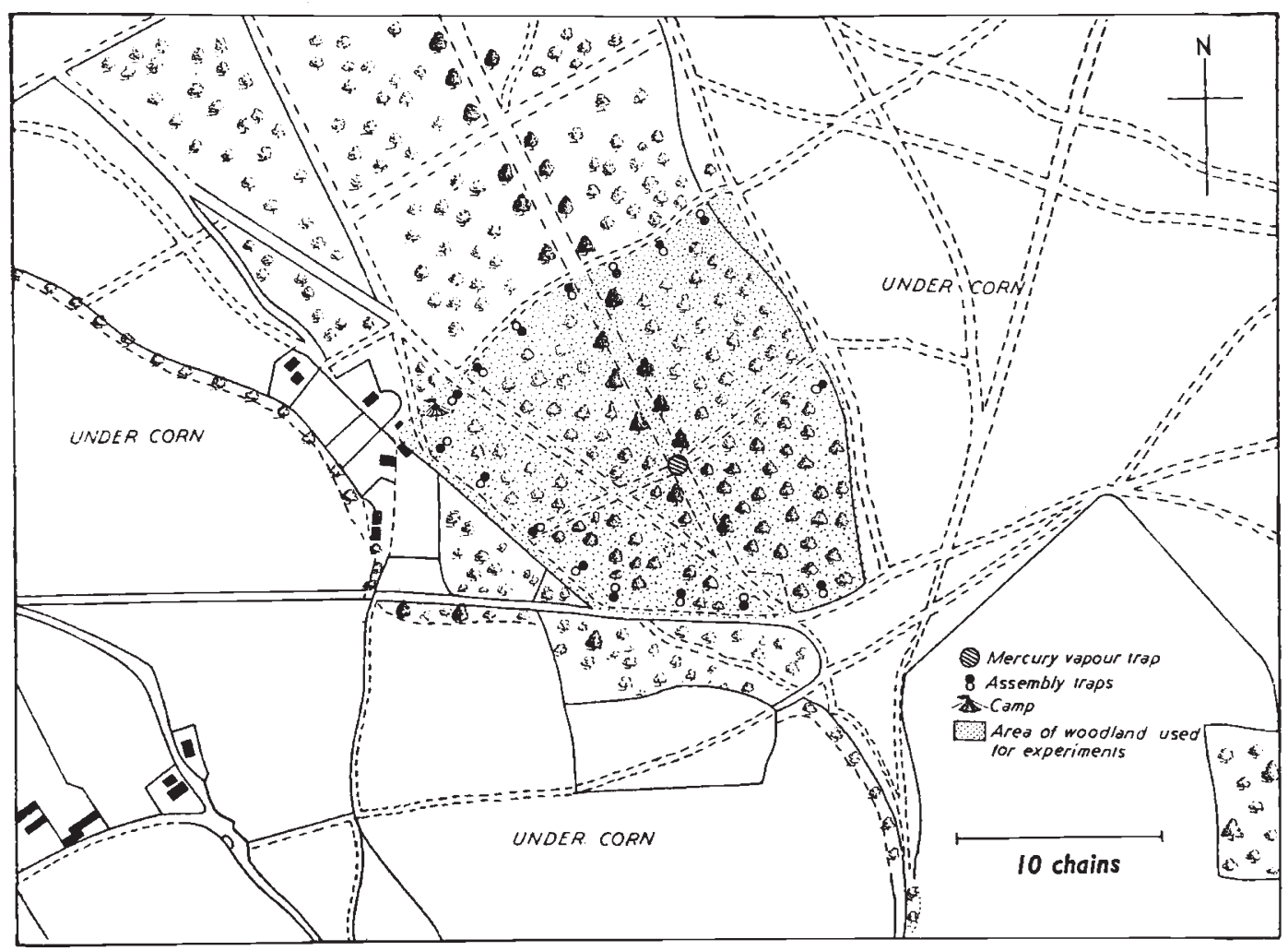

FIG. 2.-Deanend Wood, Dorset. Drawn by Miss Christine Court.

no carbonaria. Furthermore, leaf washings from locally collected samples showed a small degree of pollution only. Accordingly, in 1955 , in mid-June, I set up camp in these woods. Suitable sheds were found to house the three thousand betularia pupæ. An electric generator with mercury vapour traps was installed in the centre ride and the periphery of the wood was lined with cages destined to contain virgin females, so that at night the whole release area would be subject to a concentration of female assembling scent and this, no doubt, succeeded in holding a proportion of our male releases within the area of woodland. 
The experiments were designed so that each aspect of the work could be compared with the previous Birmingham results, and the methods employed came under the following headings :

(I) Scoring values as gauged by human standards.

(2) Direct observation as to what happened to the individuals so scored.

(3) Recapture figures which provided data over longer periods.

On every occasion, recapture results were assessed on male Peppered Moths only, because of the impossibility of recapturing females. However, these were used as releases for continuous observation from hides where, at the same time as a film record which was made, the order of predation of each insect was noted.

\section{(i) Scoring values for crypsis}

The technique of scoring previously used was to assess, in the first place at a distance of two yards, whether a released moth was (a) conspicuous, or $(b)$ inconspicuous. Subsequently, three categories were allowed for each, so that the score for $(a)$ would be either - I, -2 , or -3 , and for $(b)+1,+2$, or +3 , depending on the distance at which the insect faded into its background. As pointed out in the previous paper, this method of scoring worked satisfactorily in the Birmingham experiments. It came as a surprise then to find that, of 120 typicals released in Deanend Wood during the first few days, all were classed as inconspicuous, with 85 per cent. scoring +3 . Conversely, all 75 carbonaria scored by us appeared conspicuous and 80 per cent. of these scored -3. In view of the random sample of the release points selected, it appeared unnecessary to continue the arduous procedure of scoring the cryptic value of each individual release, and it was accepted that in these woods, to the human eye, the majority of the light typical form were extremely well hidden, and the carbonaria were nearly always conspicuous (plate I, fig. I).

\section{(ii) Direct observation}

(a) $A$ record of the number of individuals present or absent by late afternoon. Early on in the experiments an apparent deficiency of the light typical form was recorded when the afternoon check on releases took place. There were also many carbonaria missing. In the present work, in regard to the other melanic insularia, the numbers used, though quoted, were so small that they have no significance. It became increasingly obvious that one was passing over the typical form on the lichened tree trunks, and they are practically impossible to see. To test this, I did a check immediately following the morning's release, in an area where my continual presence prevented predation. All the carbonaria were present, but over 30 per cent. of the typicals were unaccounted for. The cryptic efficiency of the typical on a lichened 
background is, in fact, greater than that of carbonaria on the blackened Birmingham tree trunks. For this reason, this type of recording was discontinued.

(b) Observation from hides. In the course of filming, Dr Niko Tinbergen, who had to spend the greater part of each day in a hide, recorded the order in which predation occurred. These figures are added to my own observations. It must be emphasised that these records were of concentrations of female betularia necessary for photography, but that they played no part in my release-recapture figures. On each occasion, an equal number of black and white forms were used at the commencement, but it was found impracticable to replace each phenotype after it had been taken. Their numbers were

TABLE 4

Direct observation on predation by five species of birds.

Deanend Wood, Dorset, I955

\begin{tabular}{|c|c|c|c|c|c|}
\hline & & Observer & Carbonaria & \multicolumn{2}{|c|}{ Typical } \\
\hline $\begin{array}{l}\text { Spotted Flycatcher } \\
\quad \text { (Muscicapa striata L.) }\end{array}$ & . & $\begin{array}{l}\text { N. T. } \\
\text { H. B. D. K. }\end{array}$ & $\begin{array}{l}46 \\
35\end{array}$ & \multicolumn{2}{|l|}{$\begin{array}{l}8 \\
\mathrm{I}\end{array}$} \\
\hline $\begin{array}{l}\text { Nuthatch } \\
\quad \text { (Sitta Europaea L.) }\end{array}$ & . & $\begin{array}{l}\text { N. T. } \\
\text { H. B. D. K. } \\
\text { H. B. D. K. }\end{array}$ & $\begin{array}{r}22 \\
9 \\
9\end{array}$ & \multicolumn{2}{|c|}{$\begin{array}{l}8 \\
\text { o (first day) } \\
3 \text { (second day) }\end{array}$} \\
\hline $\begin{array}{l}\text { Yellow Hammer } \\
\quad \text { (Emberiza citrinella L.) }\end{array}$ & . & $\begin{array}{l}\text { N. T. } \\
\text { H. B. D. K. }\end{array}$ & $\begin{array}{r}8 \\
12\end{array}$ & \multicolumn{2}{|l|}{$\begin{array}{l}\text { o } \\
\text { o }\end{array}$} \\
\hline$\underset{\text { (Erithacus rubecula L.) }}{\text { Robin }}$ & . & N. T. & 12 & \multicolumn{2}{|l|}{2} \\
\hline $\begin{array}{l}\text { Thrush } \\
\text { (Turdus ericetocum L.) }\end{array}$ & . & N. T. & II & \multicolumn{2}{|l|}{4} \\
\hline \multicolumn{2}{|c|}{$\begin{array}{l}\text { Total predation observed (for days } \\
\text { when records were kept) }\end{array}$} & $\ldots$ & I 64 & 26 & $\begin{array}{l}\text { Total } \\
\text { I90 }\end{array}$ \\
\hline
\end{tabular}

Note.-On all occasions these observations commenced with equal numbers of both phenotypes. We replaced them when all of one phenotype had been taken.

replenished after the last of one phenotype had been eaten, thus preventing simple statistical analysis. By doing this, it will be appreciated that the bias was, thereafter, in favour of that phenotype which had been eliminated previously, and it was found that on the majority of occasions the more conspicuous of the two forms were all taken before any of the others. This behaviour was common to five species of birds to a greater or lesser degree, as will be seen from the figures in table 4 (plate I, fig. 3 , and plate II, figs. I, 2, 3 and 4 ).

\section{(iii) Recapture results}

Releases were undertaken on fourteen occasions in all, making a total of 969 individuals, 473 being carbonaria and 496 typical. I 
recaptured 30 carbonaria and 62 typical. For all types of release we got back 12.5 per cent. of the typical form, but only $6 \cdot 3$ per cent. of the carbonaria. For various reasons about to be discussed, the releases on three days should be excluded from this total as they are unduly biased in one way or another. This gives a figure of 799 releases

TABLE 5

Release experiment figures for Biston betularia (males only).

Deanend, Dorset, 1955

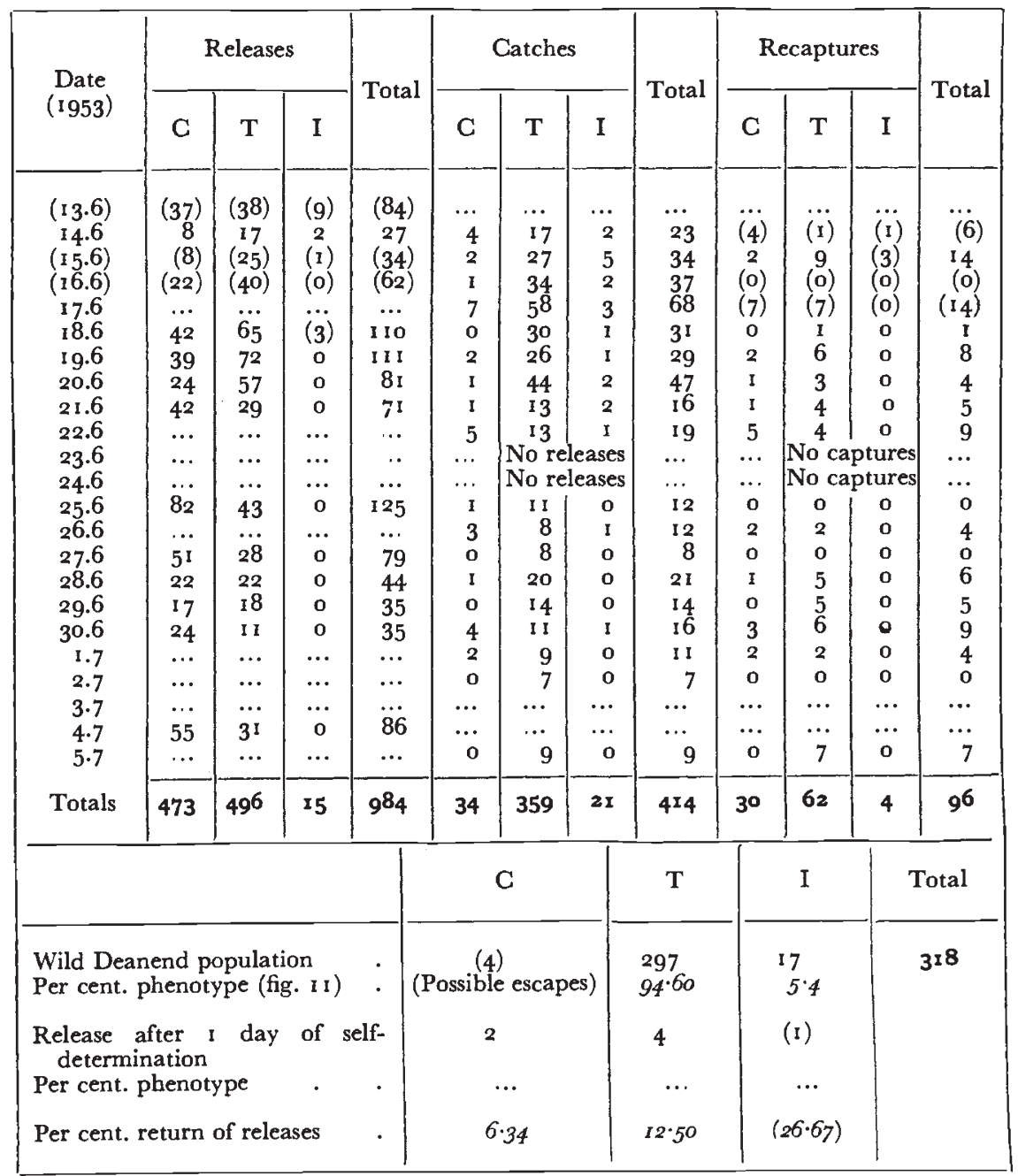

for the I I correct days: 406 being carbonaria and 393 typical. I got back I9 carbonaria and 54 typical, being 4.68 and 13.74 per cent. respectively (see tables 5 and $5 \mathrm{~A}$ ).

\section{DISCUSSION AND RELEASE PROBLEMS}

Various types of release techniques were undertaken with the object of finding the best way of subjecting as many individuals as 
possible, under natural conditions, to maximum predation for the longest time. I propose, therefore, to discuss these in some detail, and to give reasons for excluding three sets of figures from the table due to the unsatisfactory nature of the releases.

I used 84 betularia in the first experiment (13/6/55). These were released on only twenty trees, the reason for this small number of release points being that I had been unable to locate and prepare the other trees in the area. The result was that $I$ produced a high concentration of moths on comparatively few tree trunks (an average of 4 per tree), nor were the two forms on every occasion released in equality per tree. The late afternoon check showed that in nearly

TABLE $5 \mathrm{~A}$

Deanend recaptures, 1955

\begin{tabular}{|c|c|c|c|c|c|c|c|}
\hline \multirow{2}{*}{ Date } & \multicolumn{3}{|c|}{ Observed } & \multirow{2}{*}{ Total } & \multicolumn{3}{|c|}{ Expected } \\
\hline & C & $\mathrm{T}$ & I & & C & $\mathrm{T}$ & I \\
\hline$(13.6)$ & (6) & (3) & (3) & (12) & $(5 \cdot 29)$ & $(5 \cdot 43)$ & $(1 \cdot 29)$ \\
\hline $\begin{array}{l}14.6 \\
(15.6) \\
(16.6)\end{array}$ & $\begin{array}{l}1 \\
\text { (o) } \\
\text { (8) }\end{array}$ & $\begin{array}{l}7 \\
\text { (1) } \\
\text { (8) }\end{array}$ & $\begin{array}{l}2 \\
\text { (o) } \\
\text { (o) }\end{array}$ & $\begin{array}{l}\text { I0 } \\
\text { (1) } \\
\text { (16) }\end{array}$ & $\begin{array}{c}2 \cdot 96 \\
(0 \cdot 24) \\
(5.68)\end{array}$ & $\begin{array}{c}6 \cdot 30 \\
(0 \cdot 74) \\
(10 \cdot 32)\end{array}$ & $\begin{array}{l}\text { o.74 } \\
(\mathrm{o} \cdot 03) \\
(\mathrm{o})\end{array}$ \\
\hline 17.6 & $\ldots$ & $\ldots$ & $\ldots$ & $\ldots$ & $\ldots$ & $\ldots$ & $\ldots$ \\
\hline $\begin{array}{l}18.6 \\
19.6\end{array}$ & $\begin{array}{l}2 \\
1\end{array}$ & $\begin{array}{l}8 \\
2\end{array}$ & $\begin{array}{l}0 \\
0\end{array}$ & $\begin{array}{r}10 \\
3\end{array}$ & $\begin{array}{l}3 \cdot 81 \\
1 \cdot 05\end{array}$ & $5 \cdot 91$ & $0 \cdot 27$ \\
\hline $20 \cdot 6$ & 2 & 4 & 0 & 6 & $1 \cdot 7^{8}$ & $4 \cdot 22$ & o \\
\hline 21.6 & 4 & 4 & 0 & 8 & $4 \cdot 73$ & $3 \cdot 27$ & 0 \\
\hline 22.6 & $\cdots$ & $\cdots$ & $\cdots$ & ... & 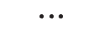 & $\cdots$ & $\cdots$ \\
\hline 23.6 & $\cdots$ & $\cdots$ & $\ldots$ & $\ldots$ & $\cdots$ & $\cdots$ & $\cdots$ \\
\hline $\begin{array}{l}\mathbf{2 4 . 6} \\
\mathbf{2 5 . 6}\end{array}$ & 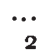 & $\dddot{m}_{2}$ & $\ddot{0}$ & $\cdots_{4}$ & $\dddot{2}_{2} \cdot \sigma_{2}$ & $\begin{array}{l}1 \cdot 38 \\
1 \cdot 38\end{array}$ & $0^{\cdots}$ \\
\hline 26.6 & $\ldots$ & $\ldots$ & $\ldots$ & & & $\ldots$ & \\
\hline 27.6 & I & 5 & o & 6 & $3 \cdot 87$ & $2 \cdot 13$ & 0 \\
\hline 28.6 & o & 7 & o & 7 & $3 \cdot 5^{\circ}$ & 3.50 & 0 \\
\hline 29.6 & 3 & 8 & 0 & II & $5 \cdot 34$ & $5 \cdot 66$ & 0 \\
\hline 30.6 & 2 & I & 0 & 3 & $2 \cdot 06$ & 0.94 & 0 \\
\hline 4.7 & o & 7 & o & 7 & $4 \cdot 47$ & $2 \cdot 5^{2}$ & 0 \\
\hline Totals & $3^{2}$ & 67 & 5 & 104 & $47 \cdot 4^{\circ}$ & $54 \cdot 27$ & $2 \cdot 33$ \\
\hline
\end{tabular}

every case the moths were either all present or all absent per tree. Subsequently, by direct observation, Dr Tinbergen and I found that a concentration of releases increased the predation risk for all present, even though the birds took the more conspicuous ones first. It will be noted that on this occasion we recaptured 4 carbonaria and I typical (expected-near equality). It is possible that, apart from a faulty release technique, a further point may have played a part in the production of these figures. The birds in this wood were unlikely to have had any previous experience of the Black Peppered Moths, and it is conceivable therefore that at first some of them did not recognise them as an article of diet. Dr Tinbergen did, in fact, record a similar incident in one of the Birmingham 1955 experiments. A Wren 
(Troglodytes troglodytes Linn.) flew on to a tree trunk on which was released a very conspicuous typical (Birmingham frequency ro per cent.) and after scrutinising it closely it flew away without attacking it. It is, however, possible that the noise of the ciné camera disturbed it at this point.

The next release (14/6/55), which was considered satisfactory, was conducted with a greatly lowered concentration. Twenty-seven betularia were, in fact, put on to 23 trees.

The release on the 15 th was designed to test whether the presence of a carbonaria on the same tree trunk as a typical lowered the latter's expectation of survival. Apart from the 8 male carbonaria released, females had, on this occasion, to be used also (because of a temporary lack of carbonaria males), so that each of the male typicals had a black moth on the same tree trunk. Two trees, however, were used as controls, and on these two typicals were released on each, with no accompanying melanics. The late afternoon examination $(6$ p.m.) gave the surprising result that no betularia of any form were to be found on any of the release trees, with the exception that one of the control trees (without a carbonaria being present) had two typicals on it. The following night, out of 37 betularia caught at light and assembling traps, none were from the releases of the $15^{\text {th }}$. The next night, however, I recaught one typical (out of 68) from this release. This would seem to provide additional evidence to the statement I made in my original paper (p. 336), "From this it would appear that, when a conspicuous insect had been found, it at once put other insects in the immediate vicinity at a disadvantage because of the bird's active seachings." For these reasons I feel that the release conducted on the $15^{\text {th }}$ should not be included.

The following day $(16 / 6 / 55)$ a release was undertaken between 5 and 6 p.m., long after the maximum predation time of birds. The object was to test whether, having excluded predation, the design of experiment favoured unduly one phenotype more than another. Twenty-two carbonaria and 40 typical were released. Of these, 7 carbonaria and 6 typical were retrapped the same night (expected$4 \cdot 6$ I to $8 \cdot 39$ ). It will be noted that this represents the return of nearly a quarter of our releases on the $\mathrm{i} 6 \mathrm{th}$. I am unable to account for the increased proportion of carbonaria recaptures over typical, which occurred this night, but in view of the absence of predation it suggests that the recapture arrangements did not unduly favour the return of the typicals more than the carbonaria. We have, however, already shown that in the Birmingham experiments there was no difference in the proportion of the three phenotypes which were collected, firstly, at mercury vapour light traps and, secondly, at assembling traps containing females of all three phenotypes (proportions of carbonaria, light and assembling, 85 per cent. to 86 per cent., and typical ro. 8 to I0.4 per cent.). Furthermore, we are able to report similar findings in this present set of experiments (see table 6). In view of these facts, 
it appeared that this release was satisfactory. One carbonaria and 6 typical were subsequently recovered.

We have produced evidence that, in undertaking any release experiments involving the use of cryptic insects which normally pass the day concealed on their appropriate backgrounds, due regard must be taken of such factors which affect predation as density, proximity of an individual which has been scored conspicuous, bird conditioning for recognition of a particular species, or for the place of release. To avoid all these complications, individual releases, undertaken over a large area containing many trees, are essential.

\section{CONCLUSIONS}

We are now in a position to review firstly, two separate series of release experiments conducted in an industrial district : secondly, to compare figures obtained from these with the data from a similar release undertaken in an unpolluted and heavily lichened wood in Dorset.

In regard to the Birmingham experiments : in the second of the two series which were carried out, scoring for crypsis was not repeated as it was unnecessary; neither the trees nor the phenotypes having altered since 1953. Direct observation on bird predation in each case showed that the typical light form was eaten more frequently than carbonaria, and the deficiency of this light form in our recapture figures can be attributed in each case to selective elimination by birds, as such other considerations as sampling errors, a different life span or migration rate for each phenotype, can be ruled out of the repeat experiment for the same reasons as given in 1953 .

On comparing the Birmingham figures for crypsis with those of Deanend Wood, Dorset, we found a complete reversal. Over 97 per cent. of the carbonaria in the former location were scored inconspicuous, whereas 89 per cent. of the typicals were adjudged conspicuous. In Deanend Wood, of the carbonaria, all were scored conspicuous, whilst of the typicals all were inconspicuous. Furthermore, of these, 85 per cent. were given the highest mark for cryptic efficiency.

Consequently the observed bird predation on both occasions in Birmingham showed elimination in favour of carbonaria. In I953, a total of i 8 betularia were kept under continuous observation, half being carbonaria and half typical. All the nine typicals were observed to be eaten by Robins and Hedge Sparrows, but only 3 carbonaria, the remaining 6 were never discovered and, in fact, survived the day up to 7 p.m. In the recent work, Dr Tinbergen recorded that a pair of Redstarts and their young took 43 typicals to I 5 carbonaria during experimental releases in which both black and light forms were used in equality (table 2 ).

On the other hand, in Deanend Wood, Dorset, the reverse was observed : 5 species of birds took Igo betularia whilst being watched (table 4). Of these, 164 were carbonaria and 26 typical. It must be 
accepted, therefore, that the carbonaria has an approximate $6:$ I advantage in Birmingham, and the reverse was true for Deanend. In regard to the recaptures, on each occasion in Birmingham I got back twice as many carbonaria as typicals, but in Deanend I recaptured three times as many typical as the melanic (text fig. $1 a$ ). Furthermore, if the collecting techniques employed were comparable in each case, it would appear that the predation intensity was greater at Deanend. Fewer individuals of each phenotype survived. This is also reflected in the nightly recapture totals (assuming, once again, that our collecting efficiency was comparable). In the 1953 large-scale Birmingham experiments, the average return within 24 hours was I9 betularia per roo releases. For Deanend, it was 9 per 100 . It is, however, the selective predation and not the total predation with which we are concerned in these present investigations.

\section{SUMMARY OF ALL THREE EXPERIMENTS}

I. The Peppered Moth, Biston betularia, is one of about seventy species of moth which are at present in the process of changing their populations from light to dark individuals. The common Industrial Melanic $=$ form carbonaria is black, and another $=$ form insularia, which is not an allelomorph, varies from light to heavily speckled specimens (plate II, fig. 6).

2. This paper records two complementary series of experiments, involving the release of nearly 2000 marked moths, to test the relative camouflage or cryptic advantages of the normal light-coloured betularia and its melanic form carbonaria. This was carried out in the first place near the industrial area of Birmingham where the carbonaria form represents about 87 per cent. of the population. Secondly, a similar experiment was undertaken in a heavily lichened and pollution-free wood in rural Dorset, where carbonaria does not normally occur or, if it does, at a very low frequency. (The other melanic, insularia, though mentioned, was used in too small numbers to have significance.)

3. The first series was a repeat of similar work I carried out in 1953, and fully corroborates the conclusions previously published (Kettlewell, r955).

4. On each occasion, the more conspicuous of the two forms was deficient in numbers amongst the recaptures; typical betularia in Birmingham and carbonaria at Deanend Wood, Dorset.

5. (i) Scoring for conspicuousness as recognised by Man, and (ii) direct observation of the released insects showed that birds were responsible for their elimination, both in polluted and unpolluted countryside, and this took place selectively in each case, and in an order which varied according to the camouflage efficiency of each phenotype in relation to its background.

6. In unpolluted and heavily lichened countryside melanic forms are maintained only by recurrent mutation, and are rapidly eliminated because of their conspicuousness. 


\section{Plate I}

FIG. I.-Typical betularia (left) and its melanic carbonaria (right) at rest on lichened tree trunk, Deanend Wood, Dorset.

Fig. 2.- Typical betularia and its melanic carbonaria at rest on lichen-free tree trunk near Birmingham.

Fig. 3.-Song Thrush, Turdus ericetorum L., examining tree trunks from the ground with a carbonaria in its beak. 


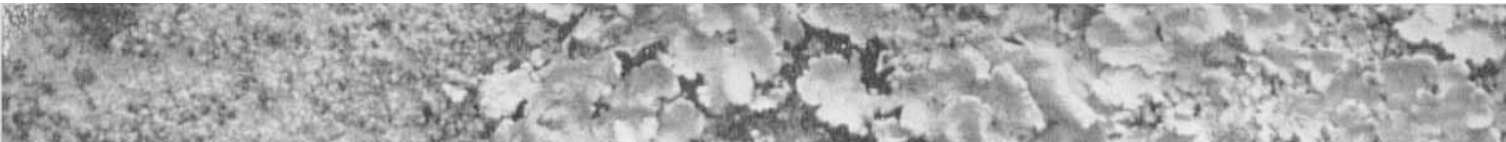

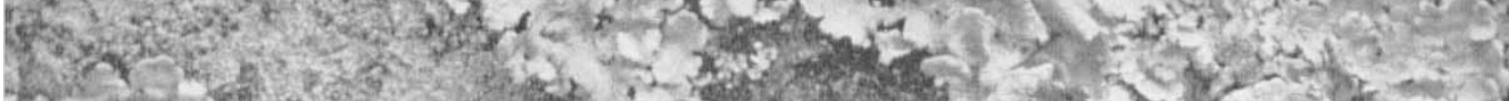

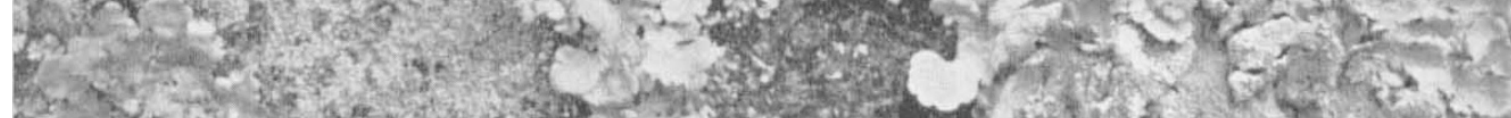
n. 4 .

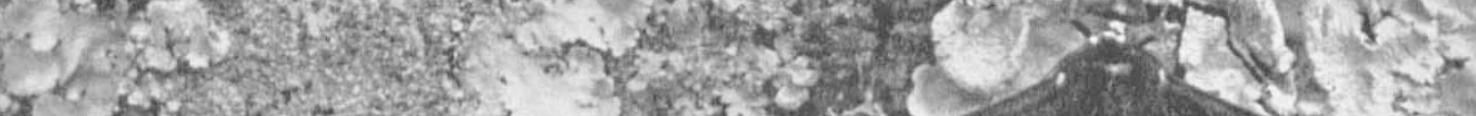
a.

2.

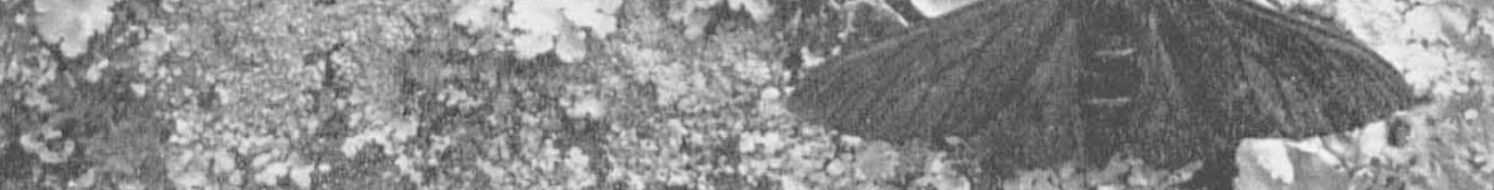

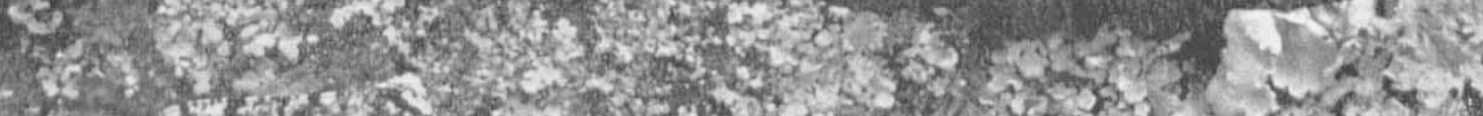

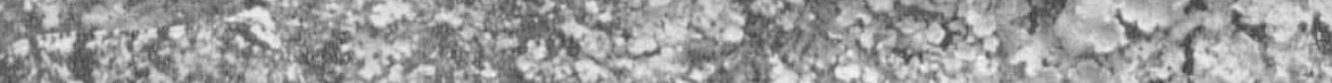

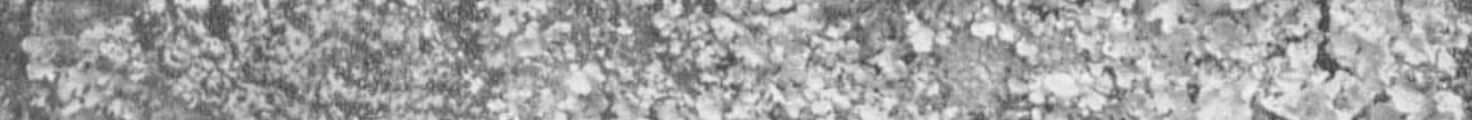

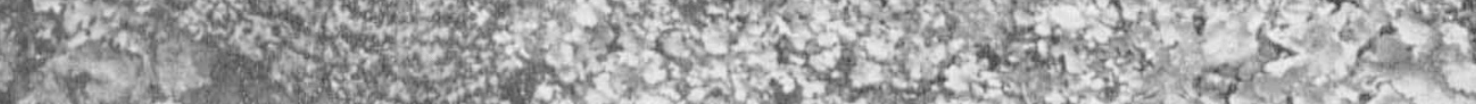

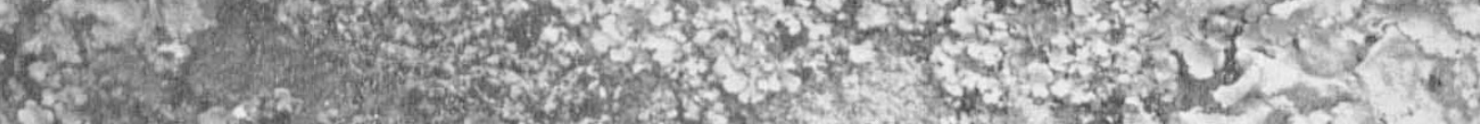

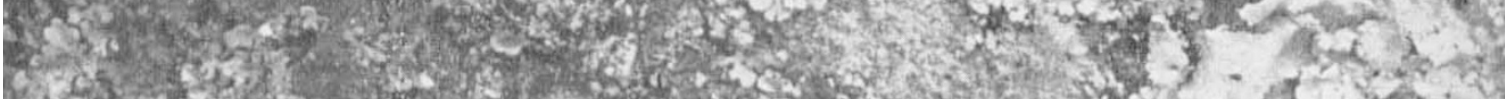

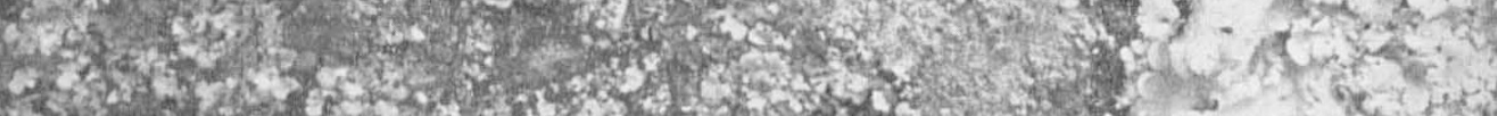

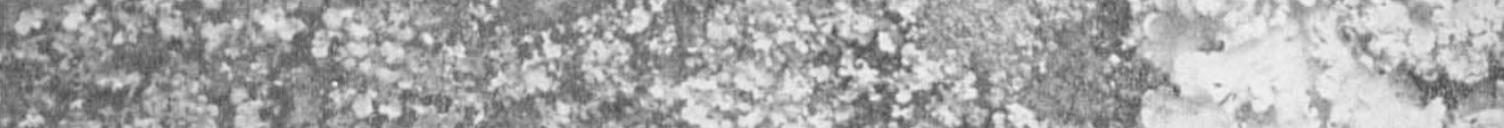

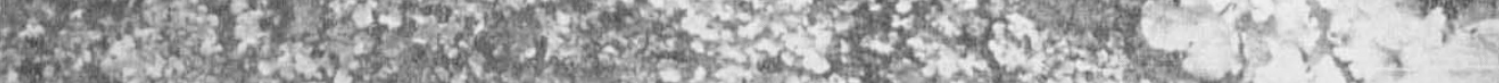

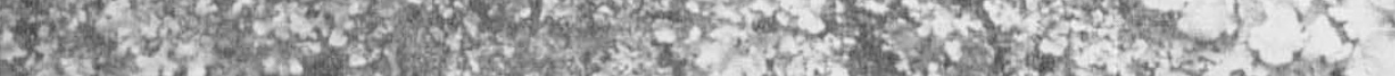

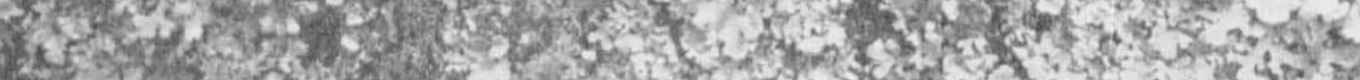

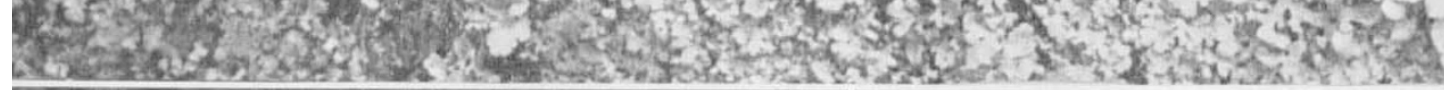
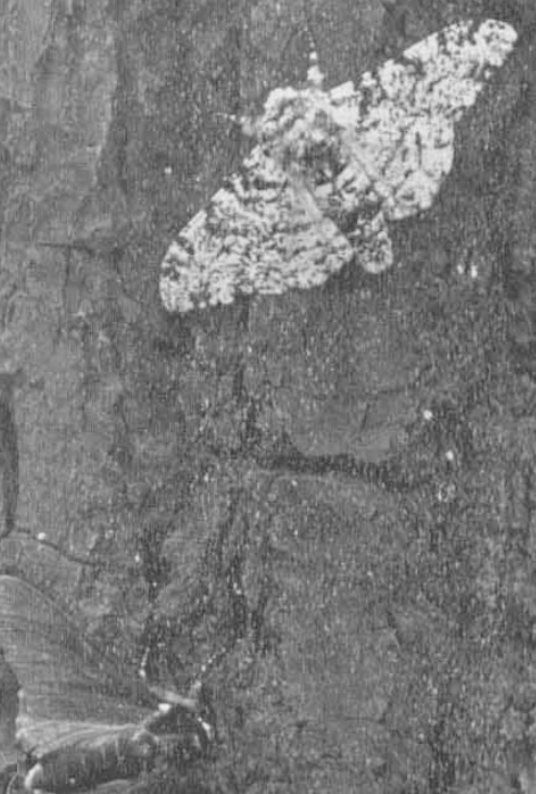


\section{Plate II}

FIG. I.-Nuthatch, Sitta europaa L., in the act of taking typical betularia from lichened tree trunk, Deanend Wood, Dorset. This species took 40 carbonaria to I I typical while under observation.

Fig. 2.-Spotted Flycatcher, Muscicapa striata L., about to take carbonaria from oak trunk, Deanend Wood, Dorset. This species was seen to take $8 \mathrm{I}$ carbonaria to 9 typical.

FIG. 3.-Robin, Erithacus rubecula L., with carbonaria in its beak taken from lichened tree trunk, Deanend Wood, Dorset. There were 3 typicals on this trunk at the moment of this photograph being taken. This species took 12 carbonaria to 2 typical whilst being watched.

FIG. 4.-Yellowhammer, Emberiza citrinella L., searching tree trunk, Deanend Wood, Dorset. A pair took altogether 20 carbonaria and on no occasion whilst under observation did they discover the typical form which, on every occasion, was offered in equal numbers to the black.

FIg. 5.-Male Redstart, Phonicurus phenicurus L., with typical betularia in its beak in a wood near Birmingham. This species took 43 typical to 15 carbonaria whilst under observation.

Fig. 6.-Typical Biston betularia L., its melanic carbonaria Jordan, and f. insularia Th-Mieg, another melanic. 
7. In industrial areas this limitation no longer exists, in fact it is the pale-coloured typical which is now eliminated. This applies also to areas far to the east of them, because of the prevailing westerly wind, where large areas of England, subject to pollution "fall-out", are deficient in lichens.

8. Predation alone is responsible for the fact that in the Birmingham district I got back only 50 per cent. of the typicals that were expected from the proportions of the two forms released. In contrast, at Deanend, it was the carbonaria form which was deficient. In fact I recaptured only 67 per cent. of the number expected.

9. The difference in cryptic coloration alone could be responsible for the rapid spread of the Industrial Melanics. There are also, however, other character and behaviour differences between them and their typical forms. These are at present the subject of investigation.

Acknowledgments.-I wish to thank the Nuffield Foundation, who have enabled me to undertake this work, also $\mathrm{Dr} \mathrm{N}$. Tinbergen for his observations and records whilst filming the experiments. I am grateful to Dr E. B. Ford, F.R.s. for his advice and to Dr P. M. Sheppard for his constructive criticism.

\section{REFERENCE}

KETtLEWELL, H. B. D. 1955. Heredity, 9, 323-342.

\section{APPENDIX}

Table IA (p. 288) reflects a different method of analysing the 1953 recaptures, to that shown in the previous paper. The original recapture figures (Kettlewell, 1 955, Table 5) record the number of marked individuals which returned each night. The present table takes into account the number of days each individual had been in the wild. Thus a recaptured insect showing three marks is entered under each of the three releasing days separately. 